Simple techniques for freeze clamping and for cutting and milling of frozen tissue at low temperature for the purpose of two- or three-dimensional metabolic studies in vivo.

Quistorff, Bjørn; Chance, Britton

Published in:

Analytical Biochemistry

Publication date:

1980

Document version

Publisher's PDF, also known as Version of record

Citation for published version $(A P A)$ :

Quistorff, B., \& Chance, B. (1980). Simple techniques for freeze clamping and for cutting and milling of frozen tissue at low temperature for the purpose of two- or three-dimensional metabolic studies in vivo. Analytical Biochemistry, 108(2), 237-248. 


\title{
Simple Techniques for Freeze Clamping and for Cutting and Milling of Frozen Tissue at Low Temperature for the Purpose of Two- or Three-Dimensional Metabolic Studies in Vivo
}

\author{
BJørn Quistorff† ANd Britton ChancE*
}

Department of Biochemistry A, University of Copenhagen, Copenhagen, Denmark, and *Johnson Research Foundation, University of Pennsylvania, Philadelphia, Pennsylvania 19104

Received April 10, 1980

\begin{abstract}
A technique is described for freeze-clamping of parenchymal tissue (e.g., liver) which causes the tissue to be rigidly fixed to an aluminium cup in the frozen state with a welldefined, reproducible orientation of the tissue as well as a minimum of morphological distortion of the major part of the sample. Furthermore, three instruments for low-temperature cutting or milling of the frozen sample for the purpose of two- or three-dimensional metabolic studies are described. The cutting and milling instruments work according to the principle of ordinary workshop machines for steel work. The frozen sample fixed in the aluminium cup may be mounted in the milling instrument and cut at the temperature of liquid nitrogen with high precision; e.g., one instrument may be adjusted to mill off tissue layers of a thickness of only $20 \mu \mathrm{m}$. Thermocouple readings from the frozen sample suggest that the milling process does not cause significant heating of the sample. This is further supported by the fact that the amount of labile metabolites, ATP, ADP, AMP, lactate, and pyruvate, is unaffected by the milling process.
\end{abstract}

Biochemical studies of the microorganization of metabolic processes in a tissue in vivo at the intercellular level require analytical techniques which provide a spatial resolution high enough to resolve metabolite gradients along the capillary. For liver tissue that implies study of metabolite gradients along the sinusoid from the portal tract to the terminal hepatic venule of the liver acinus $(1,2)$. Current sophistication of nondestructive techniques such as ${ }^{31} \mathrm{P}$ NMR (3) or IR spectroscopy (4) does not provide this resolution. It appears that only freezetrapping combined with either chemical analysis of microdissected samples (5) or various spectroscopic scanning techniques (6-8) allow these types of studies.

The present paper describes a number of techniques which have been developed as tools in such regional metabolic studies,

† Correspondence to: Bjørn Quistorff, Department of Biochemistry A, Blegdamsvej 3, 2200 Copenhagen, Denmark. aimed at a comparison between anatomical structure and spatial biochemical organization of various body organs in vivo $(5,8-14)$.

A freeze-clamping technique is described which has been designed to offer an optimal compromise between the desire of efficient quenching of metabolic processes and minimal distortion of tissue morphology. Furthermore, three simple instruments for tissue milling at low temperature are described.

\section{MATERIALS AND METHODS}

\section{Milling Instruments}

Three different low-temperature tissuemilling instruments, constructed for different purposes, are described below.

Instrument $I$. The instrument shown in Fig. 1 was designed for cutting of rather large tissue samples. The milling takes place with the sample as well as the cutting tool 


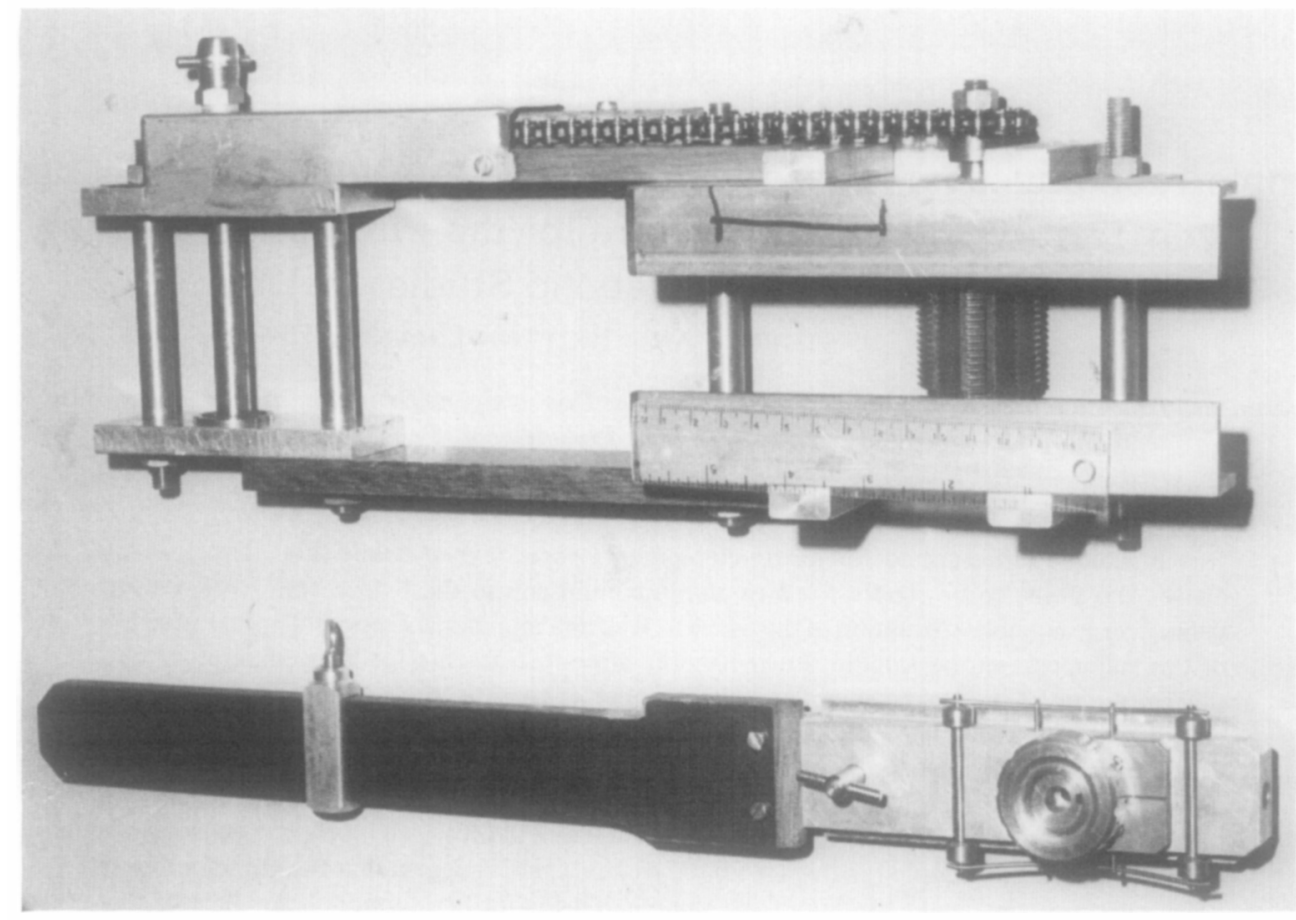

FIG. 1. Low-temperature tissue miller (see text and legend to Fig. 2).

submerged under liquid nitrogen in a Styrofoam Dewar. The function of the instrument may be outlined on the basis of the simplified diagrams in Fig. 2A: a sample cup to which the tissue sample is mechanically fixed by freeze-clamping (see later) is clamped to a micrometer screw on a removable holder. The holder moves vertically while the micrometer screw moves the sample horizontally relative to the cutter. During operation, the sample is adjusted by the micrometer screw above the liquid nitrogen, to a position where the desired tissue layer will be milled off when the holder is moved downward against the rotating cutter wheel. The aluminium frame of the instrument is constructed in two parts connected with heat insulating material (Perspex) which prevents the upper part from frosting. The cutter mounted in the lower frame in open ball bearings is driven by an electrical hand drill via a chain at a speed of $1300 \mathrm{rpm}$. The cutter is an ordinary milling tool designed for coarse steel milling (Sneholt \& Nielsen
Inc., Copenhagen, Denmark) of cylindrical shape, $40 \mathrm{~mm}$ long, and $40 \mathrm{~mm}$ in diameter. There are 12 parallel rows of teeth, each row offset relative to the former by $1 / 12$ th of the distance between two teeth. Thus, if the sample holder is advanced by $0.5 \mathrm{~mm} / \mathrm{s}$, each tooth will remove tissue fragments approximately $4 \mu \mathrm{m}$ thick. An increase in feeding speed to more than $1-2 \mathrm{~mm} / \mathrm{s}$ at a depth of cut of $200 \mu \mathrm{m}$ or more will result in macroscopically visible grinding marks on the tissue surface. The principle of the micrometer screw used to control the position of the sample relative to the cutter is explained in Fig. 2B. The micrometer allows sections of a thickness of down to 50 $\mu \mathrm{m}$ to be milled off at a time.

Figure 3 shows a reversible modification of the instrument which was constructed in order to obtain large amounts of milling powder (see Discussion). The instrument allows automatic, simultaneous milling of up to eight samples. The samples are mounted on a disk which rotates and is moved up- 
ward relative to the cutter (see legend to Fig. 3), at a speed adjusted to give a depth of cut of each tooth on the milling tool of approximately $4 \mu \mathrm{m}$.

Instrument $I I$. The second instrument shown in Figs. 4 and 5 is a versatile combination of a miller and a mini-buzz-saw, designed for operation in a refrigerated glove box

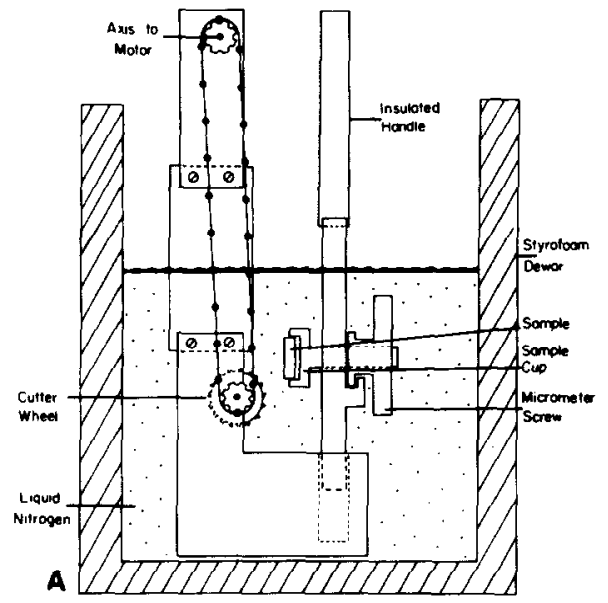

B

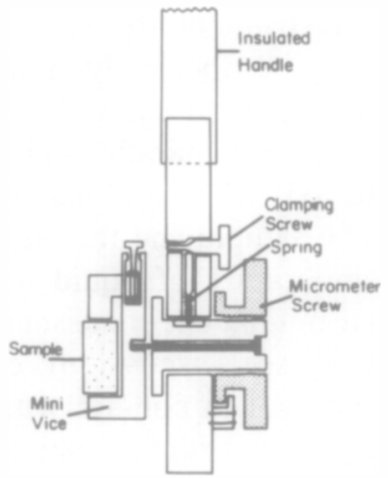

FIG. 2. Low-temperature tissue miller. (A) The instrument is operated in liquid nitrogen. Milling takes place by moving the sample holder downward against the rotating cutter. The thickness of the cut may be preadjusted on the micrometer screw on the sample holder. (B) The micrometer screw and the nut to which the sample cup is fixed are both made of brass which were found to operate smoothly in liquid nitrogen. The pitch of the screw is $1 \mathrm{~mm}$. To gain sufficient stability during milling, the micrometer screw can be locked by means of a conical clamping screw.

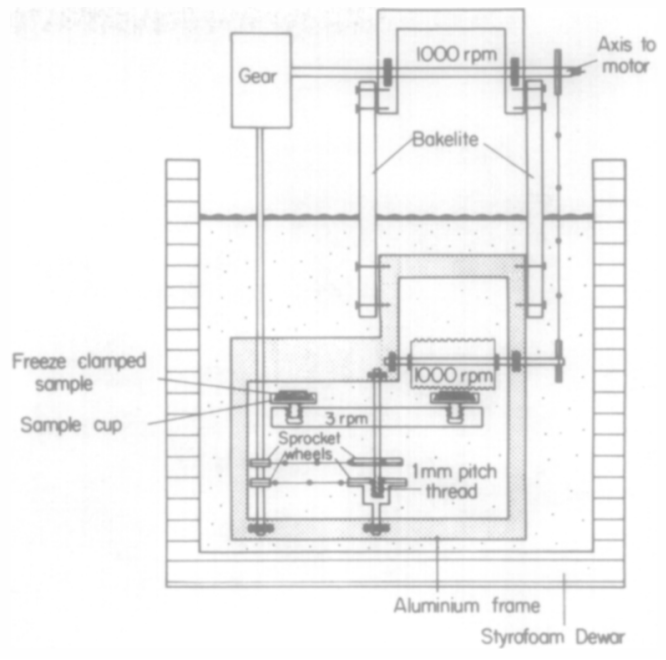

FIG. 3. Low-temperature multisample miller. The motor which drives the cutter also drives a horizontally oriented disk (12 cm in diameter), on which eight samples are clamped in special sample holders (see Freeze-clamping tongs). On the lower end of the axis of the disk a sprocket wheel is threaded on, which is driven at a speed of 0.9 times the speed of the disk. Thus for each turn the disk is elevated by $0.1 \mathrm{~mm}$ and, consequently, a tissue layer of $0.1 \mathrm{~mm}$ is milled off the surface on each sample. The tissue powder is easily collected from the bottom of the Dewar after sedimentation.

between -20 and $-30^{\circ} \mathrm{C}$ with intermittent cooling of the tissue sample in liquid nitrogen during cutting. It may be operated either freehandedly or with various cutting supports. The milling support, Fig. 5A, to which the different sample holders (see later) are easily clamped, ensures that a series of cuts in the sample will be exactly parallel even when the sample is demounted temporarily. The milling tool used is a highspeed shaft cutter (Sneholt \& Nielsen, Inc.), $14 \mathrm{~mm}$ in diameter with four bits at an angle of rifling of $135^{\circ}$. With this tool, a speed of rotation of $3500-4000 \mathrm{rpm}$ and a speed of feeding of approximately $1 \mathrm{~mm} / \mathrm{s}$ gives a perfectly smooth tissue surface. The difference in level of the two lands, i.e., the thickness of the cut, is continually adjustable (see Fig. 5B). However, cutting of more than $250 \mu \mathrm{m}$ at a time will decrease the 


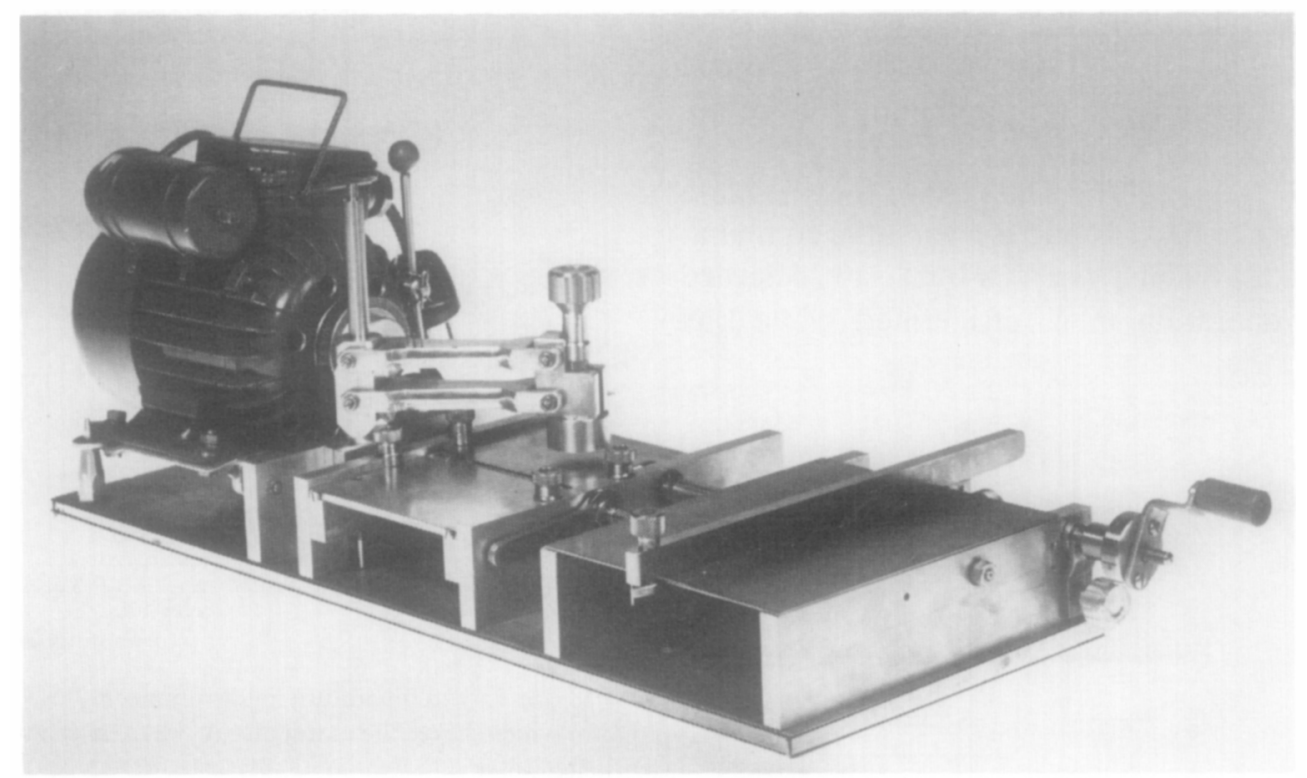

FIG. 4. Combined low-temperature tissue miller and saw (see legend to Fig. 5 and text for details).

quality of the cut, i.e., macroscopically visible cutter marks on the surface may be seen. A tray underneath the cutter collects about $80 \%$ of the milling dust which may be used for metabolite analysis (see later) (12).

The buzz saw (see Fig. 4) is driven from the same motor as the miller via a clutching mechanism which, for reasons of safety, may be released when the miller is operated. The saw blade is a high-speed steel cutting blade (purchased from G. Nelholdt, Inc., Copenhagen, Denmark), $50 \mathrm{~mm}$ in diameter, usually $0.20 \mathrm{~mm}$ thick, tapered toward the center by $0.01 \mathrm{~mm}$ on each side. The tooth height is $2.5 \mathrm{~mm}$. With this blade, a speed of rotation of $800 \mathrm{rpm}$ is found to give good results. The saw is equipped with a side support which is continually adjustable by means of a micrometer screw with an accuracy of $0.1 \mathrm{~mm}$ (see Fig. 4). The maximum depth of the cut is $12 \mathrm{~mm}$. On freezeclamped brain samples it is possible to cut slices as thin as $0.7 \mathrm{~mm}$ on which different regions are easily punched out (13-15). Slices thinner than $0.7 \mathrm{~mm}$ will fall apart during the cutting. On liver this limit is $1.5-2 \mathrm{~mm}$.
Instrument III. The third milling instrument shown schematically in Fig. 6 was constructed as part of a computer-operated 3-D scanning microfluorometer, requiring milling of a $1-$ to $2-\mathrm{cm}^{2}$ surface to a precision of $20 \mu \mathrm{m}$ at liquid nitrogen temperature. ${ }^{1}$

In this instrument the sample cups are mounted in a thermally insulated box directly clamped to an $x-z$ stage, which allows movements parallel and perpendicular to the axis of a stationary miller (see Fig. 6). The sample and the cutter are kept at the temperature of liquid nitrogen, ensuring that milling occurs essentially at this temperature (see Discussion), even though the cutter is not in contact with the liquid $\mathrm{N}_{2}$ during the milling, which lasts approximately $30 \mathrm{~s}$. In Fig. 6 the instrument is shown in the scanning position with the cutter half submerged in liquid nitrogen. The milling process starts by lowering the box (and thereby the sample) to a position where the sample surface is above the plane

\footnotetext{
1 The computer-operated scanning microfluorometer will be described in extenso elsewhere. The instrument has been applied in a number of 3-D metabolic studies in vivo $(10,11,16)$.
} 
of the cutter by an increment equal to the amount of tissue to be milled off. The cut is performed by moving the box horizontally along the $x$ axis. In order to gain precision, the thermal gradient along the shaft of the miller is kept as steep as possible by regulated hot air heating of the lower bearing as well as the inside of the shaft. The cutter is a $60^{\circ}, 16$-bit angular cutter with a diameter of $40 \mathrm{~mm}$ (purchased from F. \& O. Tool Co., Inc., Three Rivers, Mass.). It is operated at a speed of rotation of $1500 \mathrm{rpm}$ with a feeding speed of $0.5-1.0 \mathrm{~mm} / \mathrm{s}$, which gives high quality of cuts as long as the thickness of the cut is less than $200 \mu \mathrm{m}$. Cuts of a thickness down to 20

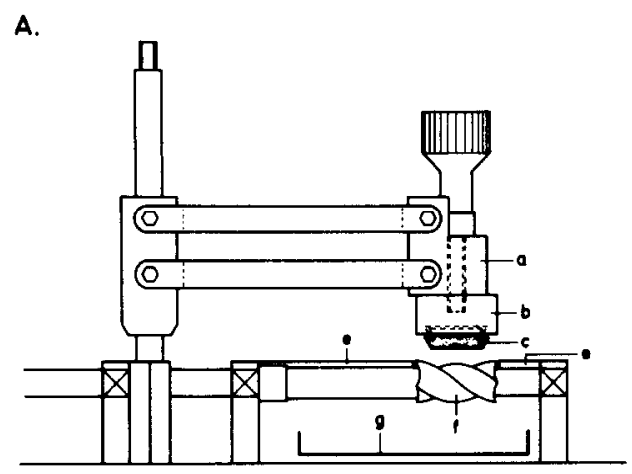

B.

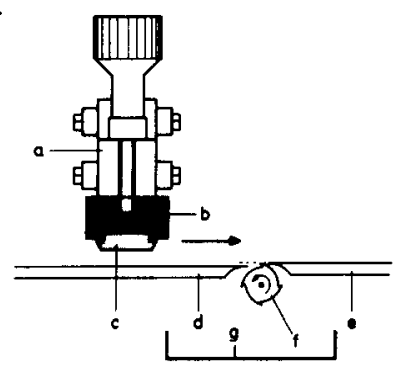

Fig. 5. Details of low-temperature tissue miller. (A) The sample cup (b) is clamped to the milling support (a) which will keep the sample surface parallel to the land of the miller (e). The milling powder is collected in the tray (g) under the cutter (f). (B) The adjustable vertical distance between the two lands, (d) and (e), determines the thickness of the cut, usually $0.1 \mathrm{~mm}$.

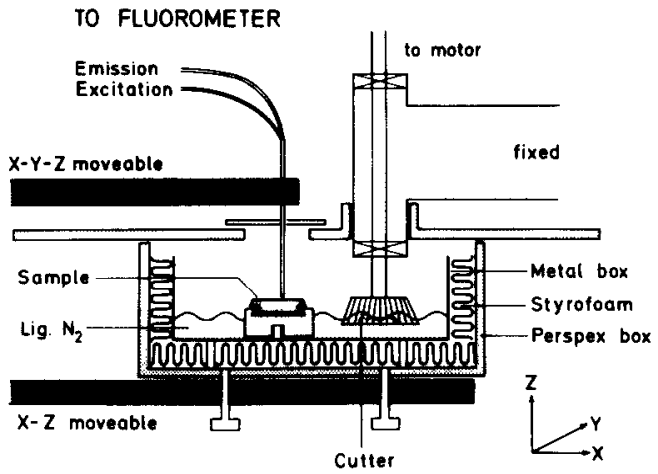

FIG. 6. Combined low-temperature tissue miller and scanning microfluorometer. Milling is performed by moving the sample relative to the rotating cutter. This is accomplished by means of the $x-z$ stage to which the scanning chamber containing the sample is clamped. The optical coupling between the microfluorometer and the sample surface is obtained by a micro-light guide (26). During scanning the light guide is moved from point to point on the tissue surface in a vertical position by means of the $x-y$ stage.

$\mu \mathrm{m}$ may be performed with this instrument. The box is provided with a lid in which a sleeve allows for the movements of the box relative to the cutter so that the box remains sealed with an atmosphere of dry nitrogen during the process of milling and scanning preventing the accumulation of frost or liquid oxygen on the sample.

\section{Freeze-clamping Tongs}

The three different milling instruments described above all operate on tissue samples obtained by various means of quick freezing. Figure 7A shows a pair of freezeclamping tongs usually used for sampling of liver tissue but useful also for any other soft tissue (e.g., heart (9)). The tongs are a modification of the Eränkö-Wollenberger tongs $(17,18)$, equipped with interchangeable clamping blocks, Fig. 7B. The tongs are hand held and allow in situ freeze-clamping of a single liver lobe of an anaesthetized rat. The liver lobe is held between the jaws of the tongs and clamped with a firm but comparatively slow movement, which will bring the sample down in the recess of the 
A

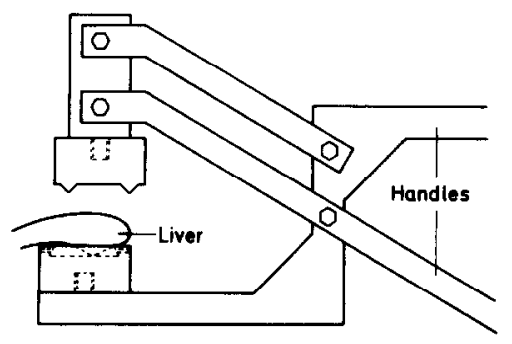

B

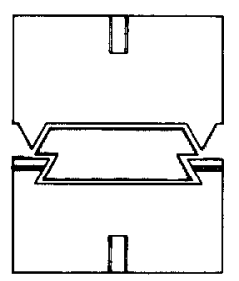

C

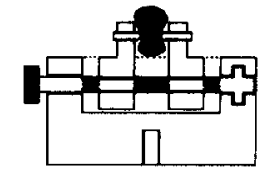

D

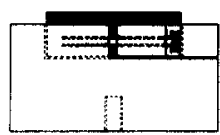

Fig. 7. Freeze-clamping tongs and different versions of sample holders. (A) The tongs are precooled in liquid nitrogen and the tissue to be clamped is held between the blocks as shown with a liver lobe. The upper as well as the lower block is removable. (B) The freeze-clamping blocks of (A) removed from the tongs after clamping of a tissue sample. The blocks are of cylindrical shape, $30 \mathrm{~mm}$ in diameter, $20 \mathrm{~mm}$ high, and are made of aluminium. During clamping the tissue is pressed down into the conical recess of the lower block, adopting the shape of the chamber formed between the two blocks. Several blocks with different size recesses have been devised. For rat liver the

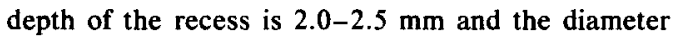
$21 \mathrm{~mm}$, increasing to $23 \mathrm{~mm}$ at the bottom. There are four horizontal channels of a bore of $1.8 \mathrm{~mm}$, connecting to the recess through the wall. The projecting annulus on the upper block has a diameter at the edge of $24 \mathrm{~mm}$, decreasing to an i.d. at the base of $20.5 \mathrm{~mm}$. The height of the annulus varies in different blocks from 1-3 mm. (C) Minivise for clamping of frozen tissue samples of irregular size, diameter $40 \mathrm{~mm}$, height $27 \mathrm{~mm}$. (D) Holder designed for brain samples lower block, filling it up completely while the projecting annulus on the upper block will cut away excess tissue and leave the original tissue surface plane parallel to the base of the blocks (see Fig. 7B). A good clamp which is easily obtained after some practice will deliver the tissue sample rigidly fixed to the lower block, partly because of the conical shape of the recess and partly due to the small channels from the recess to the outside of the block into which liver tissue is pressed during clamping (see Fig. 7B).

Tissue samples which are not readily fixed to sample cups by freeze-clamping as described above, e.g., the rat brain, may also be worked up on the milling instruments, using a minivise as sample holder. Two versions of the minivise are shown in Figs. 7C and $\mathrm{D}$. The physical dimensions are similar to the sample cups of Fig. 7B, so it will fit the various milling instruments. Brain tissue may be sampled in vivo with the Guillotine freeze-clamping instrument (15) which delivers frozen samples of uniform cylindrical shape. These samples are easily mounted in the type of cup shown in Fig. 7D. Alternatively, freezing by irrigation of the head with a suitable coolant may be used for brain sampling (19). The frozen head is then cut on the buzz saw (instrument II) trimming a tissue block of suitable size for mounting in the minivise, shown in Fig. $7 \mathrm{C}$.

\section{Experiments on Rat Liver}

Fed, male Wistar rats, weighing 250$350 \mathrm{~g}$ were used. The animals were anaesthetized with sodium pentobarbital, 75 $\mathrm{mg} / \mathrm{kg}$ ip.

Thermocouple recordings. A thermocouple (hypodermic needle, $0.7 \mathrm{~mm}$ in diameter, EL-Lab., Inc., Copenhagen, Denmark) was inserted in a liver lobe in situ.

obtained with the guillotine freeze-clamping instrument (15), diameter $40 \mathrm{~mm}$, height $26 \mathrm{~mm}$. The sample holders shown in (B), (C), and (D) will all fit the different milling instruments. 
The lobe then was excised and freeze clamped within 5-7 s applying the tongs shown in Fig. 7A. A small groove was made in the projecting annulus of the upper block in order to allow complete closing of the tongs with the needle in place in the sample. In the frozen state the needle became located parallel to the sample surface, with the thermojunction in the middle of the sample (i.e., all parts of the thermojunction experienced roughly the same cooling time). The frozen sample with the thermocouple was transferred to the glove box in a liquid nitrogen container and milled on instrument II (described above) while the thermocouple potential was continuously recorded. The lands of the milling instrument was then adjusted to equal height above the level of the cutter (see Fig. 5B) and the sample was moved across the miller, again recording the temperature time course, but without cutting. The actual location of the thermocouple in the frozen sample was determined as described previously (13).

Metabolite measurements. A liver lobe was excised and freeze-clamped within $5-7 \mathrm{~s}$ as before. The sample was transferred to the glove box at $-25^{\circ} \mathrm{C}$ in which instrument II was operated. On all samples the top $50-100 \mu \mathrm{m}$ of tissue was milled off and the powder discarded. On different samples two series of experiments were performed:

(a) With a scalpel approximately $20 \mathrm{mg}$ of tissue was scraped off evenly from half the sample surface while the sample was cooled in liquid nitrogen. The other half of the sample then was milled to the samc level and about $20 \mathrm{mg}$ of powder collected. The two samples (the powder obtained by scraping with the scalpel and the milling powder) were weighed on a balance in the glove box and extracted as described below.

(b) The freeze-clamped sample was milled a number of times to a depth below the surface of approximately $500 \mu \mathrm{m}$. The pooled, mixed milling powder was divided in five equal portions which were weighed (approximately $20 \mathrm{mg}$ ) and then stored in sealed tubes in the glove box at $-25^{\circ} \mathrm{C}$ to be extracted after 10, 30, 50, 90, and $180 \mathrm{~min}$ of storage.

Analytical techniques. All samples were extracted with $\mathrm{HCl} /$ methanol $(0.1 \mathrm{~N} / 100 \%)$ in the glove box at $-20^{\circ} \mathrm{C}$, reextracted with perchloric acid $(0.6 \mathrm{M})$ at $0^{\circ} \mathrm{C}$, and finally neutralized with $\mathrm{KOH} /$ imidazole $(2 \mathrm{M} / 0.3$ M) essentially as described by Lowry and Passonneau (20). Standard enzymatic metabolite assays for adcnine nucleotides, lactate, and pyruvate were performed on the neutralized tissue extracts. ATP and lactate were measured spectrophotometrically, while pyruvate, ADP, and AMP were measured fluorometrically according to Lowry and Passonneau (20). Internal standards, added to the $\mathrm{HCl} /$ methanol extract were recovered by $97-106 \%$.

\section{RESULTS}

\section{Thermocouple Measurements}

In order to test whether significant heating of the tissue occurs during low-temperature milling, the temperature has been recorded with a thermocouple in liver samples during freeze-clamping and in the frozen sample during milling with instrument II. Figure $8 \mathrm{~A}$ displays the timetemperature relation in the center of the liver sample during clamping. Closing of the precooled tongs on the sample defines zero time. The distance from the center of the thermocouple to the nearest metal-tissue interface was $1.6 \mathrm{~mm}$ in this particular experiment. At this distance, the time needed to cool from 37 to $0^{\circ} \mathrm{C}$ was $2.2 \mathrm{~s}$.

Figure $8 \mathrm{~B}$ shows the records of the temperature-time course in the same sample when taken from the container with liquid nitrogen and moved across the miller, with or without cutting (see Methods). The temperature-time courses obtained with the two procedures are virtually identical: following the transfer of the sample from the liquid nitrogen container to the milling 


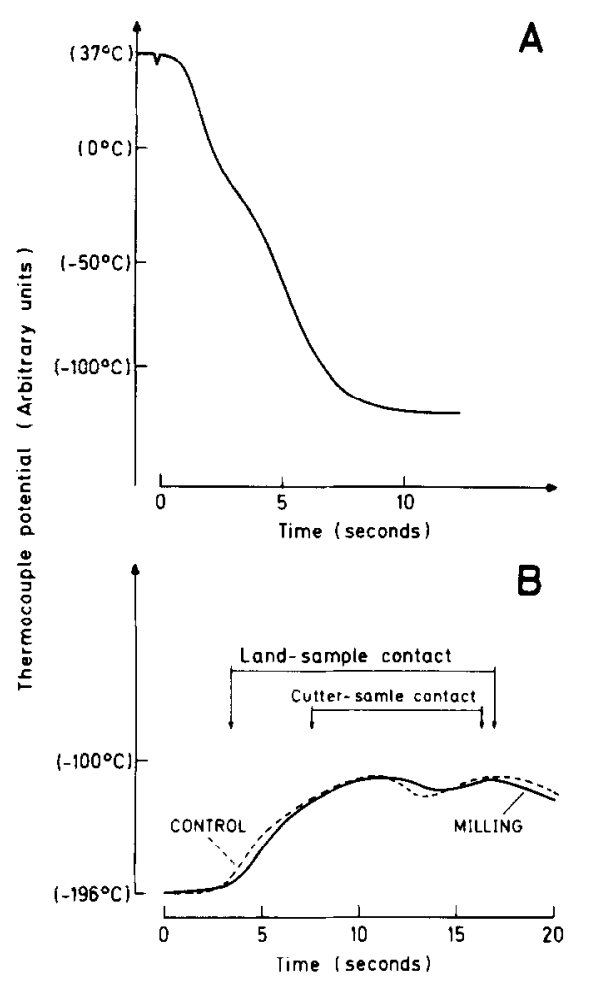

FIG. 8. Thermocouple recordings in rat liver. (A) During freeze-clamping; (B) in the frozen sample during low-temperature milling.

instrument, there is a fast temperature rise. After a few seconds a temperature gradient is established across the tissue from the land of the milling instrument, at $-25^{\circ} \mathrm{C}$, to the aluminium cup, at about $-190^{\circ} \mathrm{C}$. Since this temperature gradient may be considered linear (21) the steady-state thermocouple reading of approximately $-120^{\circ} \mathrm{C}$ defines the location of thermojunction in the sample in a simple way, i.e., the distance from the thermojunction to the surface in contact with the aluminium block is given as (190$120 / 190-25$ ) times the thickness of the frozen sample. In this particular experiment the sample thickness was $4 \mathrm{~mm}$. Accordingly, the distance from the aluminiumtissue interface to the thermojunction may be calculated to $1.7 \mathrm{~mm}$ which agrees well with the measured value of $1.6 \mathrm{~mm}$. Both curves display a trough of about equal size corresponding to the time interval when the part of the sample containing the thermojunction is moved across the gap between the two lands. In conclusion, the fact that the two traces display practically identical temperature-time course, strongly suggest that the amount of heat generated by the milling processes is negligible.

\section{Metabolite Measurements}

Two series of experiments have been carried out in order to evaluate whether the handling or the milling of the frozen tissue in the glove box at $-25^{\circ} \mathrm{C}$ introduce changes in the concentrations of labile metabolites in rat liver. Since instrument II is operated at a higher temperature $(-30$ to $-20^{\circ} \mathrm{C}$ ) than the two other instruments $\left(-196^{\circ} \mathrm{C}\right)$, milling with this instrument was most likely to cause a change in metabolic state in the tissue. Consequently, only instrument II was tested as described below.

In the first series of experiments, metabolite concentrations were compared in two sets of samples from the same freezeclamped liver sample, obtained either by milling or by scraping with a scalpel (see Methods). The results are given in Table 1. The concentrations obtained are in agreement with the values usually found in rapidly freeze-clamped rat liver from barbiturateanaesthetized rats $(22-24)$. The two methods of sampling (the A and B procedure) (see Table 1) give identical values for the adenylates, lactate, and pyruvate, indicating that the milling process does not cause a heat-induced change of the metabolite pattern of the liver, as judged by these metabolites. The fact that the fine tissue powder produced during milling does not stick to the cutter or clot up in the collecting tray, supports the suggestion that only insignificant heat is produced by the milling process.

In the second series of experiments, milling powder was stored in sealed tubes in the glove box for various periods of time prior to extraction. These results, shown in 
TABLE 1

Concentrations of Labile Metabolites in Freeze-Clamped Rat Liver ${ }^{a}$

\begin{tabular}{|c|c|c|c|c|c|c|c|c|}
\hline Procedure & ATP & ADP & AMP & $\sum A X P$ & ATP/ADP & Lactate & Pyruvate & $\mathbf{L} / \mathbf{P}$ \\
\hline$A^{*}$ & $3.38 \pm 0.054$ & $0.813 \pm 0.044$ & $0.130 \pm 0.007$ & $4.43 \pm 0.074$ & $4.42 \pm 0.23$ & $1.51 \pm 0.10$ & $0.237 \pm 0.022$ & $7.26 \pm 0.82$ \\
\hline $\mathrm{B}^{*}$ & $3.44 \pm 0.11$ & $0.807 \pm 0.049$ & $0.145 \pm 0.013$ & $4.48 \pm 0.093$ & $4.56 \pm 0.31$ & $1.50 \pm 0.11$ & $0.246 \pm 0.023$ & $7.01 \pm \mathbf{0 . 9 9}$ \\
\hline
\end{tabular}

${ }^{a}$ A liver lobe from a Pentothal-anaesthetized rate was excised and freeze clamped within $5-7 \mathrm{~s}$. Tissue powder was collected in the frozen state from the surface of the sample either by low-temperature milling (A) or by scraping with a scalpel (B). The metabolite concentrations are given as $\mu \mathrm{mol} / \mathrm{g}$ wet wi $\pm \mathrm{SEM}$

* Paired data $t$ test shows no significant difference between the $\mathrm{A}$ and $\mathrm{B}$ procedure for any of the parameters measured, $t_{\mathrm{d}}<1.1, n=13$.

Table 2, indicate that storage of tissue powder at $-25^{\circ} \mathrm{C}$ for a period of at least $50 \mathrm{~min}$ prior to extraction is acceptable for liver tissuc as far as these metabolites are concerned. The usual milling and extraction procedure does not involve storage of the unextracted milling powder for more than $15-30 \mathrm{~min}$. It is essential, however, that the unextracted powder is stored in sealed tubes, since significant freeze-drying may be detected already after 15 min of "open" storage in the glove box.

\section{DISCUSSION}

\section{Tissue Milling}

The milling and cutting instruments described in this paper were designed for cutting frozen tissue samples at very low temperatures for different types of threedimensional metabolic studies in vivo (814). The techniques provide an alternative to microtome cutting which is usually used for such studies $(2,5)$. Compared with microtome cutting, the advantages of tissue milling are simple and versatile operation, possibility of the cutting of large samples, and low cost of the instrument.

At low temperature, tissue becomes hard enough to apply standard workshop procedures on the frozen sample, such as cutting with a saw, drilling, or milling. It was found that certain steel cutting tools (see Methods) could be used with good results, provided the tool as well as the sample were sufficiently cooled during cutting. The common workshop experience, that a dull-as opposed to a sharpcutter gives a bad finish and produces much more heat during cutting, also applies to tissue milling. The durability of the cutting tools is generally rather good; the milling tools of instruments I and III have not been replaced so far, after a total of more than 20 and $30 \mathrm{~h}$ of continuous operation, respectively (for instrument III, $30 \mathrm{~h}$ of operation corresponds to about 4000 single cuts). The cutter of instrument II has been replaced once after approximately 3000 cuts. However, the saw blade of instrument II (Fig. 5) is much less durable. This instrument is used mostly for cutting brain slices for the purpose of regional sampling of cortical tissuc $(13,14)$ and in this application, the thin blades wear down after 30-50 cuts. The blades are relatively cheap (\$6-7), however, and are easily replaced.

\section{TABLE 2}

Concentrations of Adenylates in Freeze-Clamped Rat Liver Samples as a Function of TIME OF STORAGE AT $-20^{\circ} \mathrm{C}^{a}$

\begin{tabular}{|c|c|c|c|c|c|}
\hline Minutes & & 10 & 50 & 90 & 180 \\
\hline ATP & 3.46 & \pm 0.22 & $10 l \pm 1$ & $102 \pm 2$ & $102 \pm 2$ \\
\hline $\mathrm{ADP}$ & 0.730 & \pm 0.066 & $97 \pm 2$ & $94 \pm 4$ & $91 \pm 4^{*}$ \\
\hline AMP & 0.128 & \pm 0.015 & $98 \pm 1$ & $105 \pm 3$ & $102 \pm 5$ \\
\hline ATP/ADP & 4.9 & \pm 0.46 & $104 \pm 1$ & $106 \pm 7$ & $110 \pm 7^{*}$ \\
\hline
\end{tabular}

${ }^{a}$ A liver lobe from a Pentothal-anaesthetized rat was excised and freeze clamped within 5-7 s. Tissue powder was collected from a frozen sample by low-temperature milling. Samples of the powder were stored at $-20^{\circ} \mathrm{C}$ to be extracted at the time indicated. The " 10 -min values" are expressed as $\mu \mathrm{mol} / \mathrm{g}$ wet $\mathrm{wt} \pm \mathrm{SEM}$, while the 50 -, 90 -, and 180 -min values are given as percentage of the former \pm SEM.

* Significant difference with respect to the " 10 -min values," $P<0.05, n=5$. 
The thermocouple measurements in Fig. 8 suggest that heating of the solid tissue block during milling with instrument II is negligible. However, since this instrument, in contrast to the two other milling instruments described, is operated at a relatively high temperature (see Methods), the milling powder might heat up for a significant period of time because of the small mass and the lack of a heat sink. On the other hand, heating of the powder to a temperature significantly above the surrounding dry atmosphere would be counteracted by evaporation, which is greatly facilitated by the favorable volume-surface ratio of the powder state. The question has been evaluated "functionally," testing whether alterations in the metabolite pattern could be detected in the milling powder, Table 1. Since no change was observed, it seems justified to conclude that tissue milling as described here does not cause significant heating and may be used without risk of changing metabolic state of the frozen tissue.

\section{Freeze-Clamping}

The main objectives in the design of the freeze-clamping tongs were (i) to minimize the distortion of the tissue architecture during clamping, (ii) to obtain an efficient tissue-to-metal contact in order to optimize the conditions for heat transfer, (iii) to obtain a reproducible orientation of the tissue sample in the frozen state, and finally (iv) to get a rigid mechanical fixation of the sample to a holder suitable for mounting in the different low-temperature milling instruments. In order to approach these goals, the dimensions of the chamber formed between the two blocks of the freeze-clamping tongs should correspond well to the size of the particular sample to be clamped. A too large sample gives significant distortion, while inadequate freezestop and poor mechanical fixation results from the clamping of a too small sample.

So far most experience has accumulated with rat liver. In this case, optimal condi- tions are a liver lobe of a thickness $10-20 \%$ larger than the height of the chamber between the blocks: upon clamping the projecting annulus of the upper block and the recess in the lower block will isolate a tissue volume of roughly cylindrical shape, slightly greater than the chamber can accommodate (see Figs. 7A and B). Consequently, a hydrostatic pressure will build up in the sample, causing the tissue cylinder to adapt to the shape of the chamber formed between the two blocks. Excess tissue seems to escape primarily through the horizontal channels in the lower block, rather than between the two blocks. This probably accounts for the fact that only minimum distortion of the central part of the frozen sample results from the clamping (12). In contrast, the usually used EränköWollenberger freeze-clamping procedure $(17,18)$ introduces a considerable distortion of the sample, since with this technique, the main objective is to flatten the sample maximally in order to reduce the freezing time for the total sample.

The increase in hydrostatic pressure in the sample during clamping facilitates good thermal contact between the tissue and the metal blocks. Under these conditions the thermal conductivity of the tissue limits the heat removal, i.e., determines the quenching time of metabolic processes in different parts of the sample. In liver, freeze-clamped in situ measurements of labile metabolites along the freezing gradient indicate that there is a zone at the surface of a thickness of about $1 \mathrm{~mm}$, where the in vivo metabolic state seems to be preserved (12).

\section{Application of the Milling Instruments}

A few examples of the applications of the instruments described above will be given. For details, the reader is referred to the original publications. Instrument I was used in combination with an early version of the low-temperature redox ratio scanner (8). This instrument was modified in collaboration with Dr. R. L. Veech, as shown in Fig. 
3 , to allow for simultaneous milling of several freeze-clamped liver samples in order to gain large amounts of milling powder. The modification was based on the observation that tissue powder produced during the milling (1300 rpm, and a feeding speed of $0.5 \mathrm{~mm} / \mathrm{s}$ ) contained a substantial number of "isolated" apparently intact mitochondria. Probably, under these circumstances, the milling process might give rise to freeze-fracturing of the tissue with liberation of isolated mitochondria. ${ }^{2}$ Actually, the tissue chips removed by one stroke of a miller tooth may be calculated to approximately the size of a single mitochondrion (see Methods).

Instrument II is operated in a refrigerated glove box at about $-25^{\circ} \mathrm{C}$ as a versatile aid in regional sampling from the freezestopped tissue samples for metabolite analysis. A series of consecutive millings have been performed on rat liver freeze clamped with the technique described in the present paper, collecting the milling powder from each section separately. Metabolite analysis on such a series of samples allows an evaluation of the efficiency of the freezeclamping process quenching the metabolic state in different parts of the sample (12). The instrument has been used in similar studies in rat brain (13), as well as in the study of regional metabolic and blood flow changes during spreading depression (14). However, in these studies the buzz saw of instrument II was employed for cutting of parallel sections about 1-mm thick, from which particular anatomical regions were isolated for analysis.

Instrument III is in use with a new version of the low-temperature scanning microfluorometer, ${ }^{1}$ in which fluorescence signals of oxidized flavoprotein and reduced pyridine nucleotide (25) are measured with high spatial resolution via a micro-light guide

\footnotetext{
${ }^{2}$ Preparation of isolated mitochondria from large amounts of freeze-dried milling powder by means of nonaqueous technique are now in progress. ( $R$. $L$. Veech, B. Quistorff, and B. Chance, in preparation).
}

(26), cf. Fig. 6. During scanning, the light guide is moved across the sample in steps of $50-100 \mu \mathrm{m}$, while the fluorescence signals are read in each position. Because of the low transparency of the frozen tissue for the wavelengths applied and the special optical geometry of the light guide (26), the fluorescence signals will originate only from the first $50-100 \mu \mathrm{m}$ of the tissue block, i.e., giving a spatial resolution of about $0.13 \mu \mathrm{g}$, corresponding in the liver to 20 hepatocytes, approximately. Therefore, by scanning consecutive surfaces obtained by low-temperature milling, it is possible to get a series of two-dimensional scans which are vertically aligned allowing a three-dimensional evaluation of the tissue redox state. Such three-dimensional scans of redox state of liver, heart, and brain tissue have been described elsewhere $(7-9,16)$.

\section{ACKNOWLEDGMENTS}

The authors wish to thank Mr. Egon Pedersen and Mr. Hasse Persson, Department of Biochemistry A, University of Copenhagen, for their work on the construction of the cooling tongs as well as instruments I and II, and Mr. Victor Legallais, The Johnson Research Foundation, University of Pennsylvania, for the construction of instrument III. Mrs. Lissi Immerdal is thanked for technical assistance with the metabolite measurements. This research was supported in part from the following USPHS grants: AA-03517, NS-15340, HL 18708, and NS 10939.

\section{REFERENCES}

1. Rappaport, A. M. (1976) Beitr. Pathol. Bd. 157, 215-243.

2. Jungermann, K., and Sasse, D. (1978) Trends Biochem. Sci. 3(3), 198-202.

3. Burt, C. T., Glonek, T., and Bárány, M. (1977) Science 195, 145-149.

4. Jöbsis, F. F. (1978) Science 198, 1264-1267.

5. Matschinsky, F. M., Hintz, C. S., Reichlmeier, K., Quistorff, B., and Chance, B. (1978) in Microenvironments and Metabolic Compartmentation (Srere, P. A., and Estabrook, R. W., eds.), pp. 149-166, Academic Press, New York.

6. Chance, B., Barlow, C., Nakase, Y., Takeda, H., Mayevsky, A., Fischetti, R., Graham, N., and Sorge, J. (1978) Amer. J. Physiol. 235(6), H809H820. 
7. Chance, B., Barlow, C., Haselgrove, J., Nakase, Y., Quistorff, B., Mathchinsky, F., and Mayevsky, A. (1978) in Microenvironments and Metabolic Compartmentation (Srere, P. A., and Estabrook, R. W., eds.), pp. 131-148. Academic Press, New York.

8. Quistorff, B., and Chance, B. (1976) in Oxygen and Physiological Function (Jöbsis, F. F., ed.), pp. 100-110, Professional Information Library, Dallas, Tex.

9. Chance, B., and Quistorff, B. (1978) in Oxygen Transport to Tissue-III (Silver, I. A., Erecińska, M., and Bicher, H. I., eds.), pp. 331-338, Plenum Press, New York.

10. Quistorff, B., Chance, B., and Takeda, H. (1978) in Frontiers of Biological Energetics (Dutton, P. L., Leigh, J. S., and Scarpa, A., eds.), Vol. 2, pp. 1487-1497, Academic Press, New York.

11. Haselgrove, J., Chance, B., Barlow, C. H., Joyce, E., Kanamuller, H., and Bruckner, M. (1978) in Frontiers of Biological Energetics (Dutton, P. L., Leigh, J. S., and Scarpa, A., eds.), Vol. 2, pp. 1515-1522, Academic Press, New York.

12. Quistorff, B., and Poulsen, H. (1980) Anal. Biochem, 108, 249-256.

13. Quistorff, B. (1980) in Cerebral Metabolism and Neuronal Function (Passonneau, J. V., Hawkins,
R. A., Welsh, F., and Lust, W. D., eds.), Williams \& Wilkins, Baltimore, in press.

14. Hansen, A. J., Quistorff, B., and Gjedde, A. (1980) Acta Physiol. Scand. 109, 1-6.

15. Quistorff, B. (1975) Anal. Biochem. 68, 102-118.

16. Haselgrove, J., Bashford, L., Barlow, C. H., Chance, B., and Mayevsky, A. (1980) Amer. $J$. Physial., in press.

17. Eränkö, O. (1954) Acta Anat. 22, 331-336.

18. Wollenberger, A., Ristau, O., and Schoffa, G. (1960) Pflügers Archiv. 270, 399-412.

19. Kerr, S. E. (1935) J. Biol. Chem. 110(3), 625-635.

20. Lowry, O. H., and Passonneau, J. V. (1972) A Flexible System of Enzymatic Analysis, pp. 124, 148, 152, 195, 213, Academic Press, New York.

21. Carslow, H. S., and Jaeger, J. C. (1959) Conduction of Heat in Solids, p. 92, Clarendon Press, Oxford.

22. Seitz, H. J., Faupel, R. P., Kampf, S. C., and Tarnowski, W. (1973) Arch. Biochem. Biophys. 158, $12-18$.

23. Dale, R. A. (1965) J. Physiol. 181, 701-711.

24. Reinauer, H., and Hollmann, S. (1966) Anaesthetist 15, 327-332.

25. Chance, B., Schoener, B., Oshino, R., Itshak, F., and Nakase, Y. (1979) J. Biol. Chem. 254(11), 4764-4771.

26. Ji, S., Chance, B., Nishiki, K., Smith, T., and Rich, T. (1979) J. Physiol. 236(3), C144-C156. 